\title{
Identification and DNA Marker Development for a Wheat-Leymus mollis 2Ns (2D) Disomic Chromosome Substitution
}

\author{
Xianbo Feng 1,2, Xin Du 1,2, Siwen Wang 1,2, Pingchuan Deng ${ }^{1,2}$, Yongfu Wang 1,2 , Lihui Shang ${ }^{1,2}$, \\ Zengrong Tian ${ }^{1,2}$, Changyou Wang ${ }^{1,2}$, Chunhuan Chen ${ }^{1,2}$, Jixin Zhao ${ }^{1,2, *}$ and Wanquan Ji ${ }^{1,2, *(D)}$ \\ 1 State Key Laboratory of Crop Stress Biology for Arid Areas and College of Agronomy, \\ Northwest A\&F University, Yangling, Xianyang 712100, China; fxb1201@163.com (X.F.); \\ duxin060031@nwafu.edu.cn (X.D.); wangsiwen2018@nwafu.edu.cn (S.W.); \\ dengpingchuan@nwsuaf.edu.cn (P.D.); wyf063575@163.com (Y.W.); slh9707@163.com (L.S.); \\ tian.zr@163.com (Z.T.); chywang2004@126.com (C.W.); chchch8898@163.com (C.C.) \\ 2 Shaanxi Research Station of Crop Gene Resources and Germplasm Enhancement, Ministry of Agriculture, \\ Yangling, Xianyang 712100, China \\ * Correspondence: zhjx881@163.com (J.Z.); jiwanquan2008@126.com (W.J.)
}

check for updates

Citation: Feng, X.; Du, X.; Wang, S.; Deng, P.; Wang, Y.; Shang, L.; Tian, Z.; Wang, C.; Chen, C.; Zhao, J.; et al. Identification and DNA Marker Development for a Wheat-Leymus mollis 2Ns (2D) Disomic

Chromosome Substitution. Int. J. Mol. Sci. 2022, 23, 2676. https://doi.org/ $10.3390 /$ ijms 23052676

Academic Editor: Robert Hasterok

Received: 24 December 2021

Accepted: 27 February 2022

Published: 28 February 2022

Publisher's Note: MDPI stays neutral with regard to jurisdictional claims in published maps and institutional affiliations.

Copyright: (C) 2022 by the authors. Licensee MDPI, Basel, Switzerland. This article is an open access article distributed under the terms and conditions of the Creative Commons Attribution (CC BY) license (https:// creativecommons.org/licenses/by/ $4.0 /)$

\begin{abstract}
Leymus mollis ( $2 n=4 x=28$, NsNsXmXm), a wild relative of common wheat (Triticum aestivum L.), carries numerous loci which could potentially be used in wheat improvement. In this study, line 17DM48 was isolated from the progeny of a wheat and L. mollis hybrid. This line has 42 chromosomes forming 21 bivalents at meiotic metaphase I. Genomic in situ hybridization (GISH) demonstrated the presence of a pair chromosomes from the Ns genome of L. mollis. This pair substituted for wheat chromosome 2D, as shown by fluorescence in situ hybridization (FISH), DNA marker analysis, and hybridization to wheat 55K SNP array. Therefore, 17DM48 is a wheat-L. mollis 2Ns (2D) disomic substitution line. It shows longer spike and a high level of stripe rust resistance. Using specific-locus amplified fragment sequencing (SLAF-seq), 13 DNA markers were developed to identify and trace chromosome $2 \mathrm{Ns}$ of L. mollis in wheat background. This line provides a potential bridge germplasm for genetic improvement of wheat stripe rust resistance.
\end{abstract}

Keywords: Leymus mollis; molecular cytogenetics; SLAF-seq; stripe rust; wheat 55K array

\section{Introduction}

Common wheat (Triticum aestivum L., $2 n=6 x=42$, AABBDD) is one of the major food crops in the world. Against the background of the prominent contradiction between population growth and the shortage of resources, wheat yield is increasingly challenged. Wheat stripe rust, caused by the fungus Puccinia striiformis $f$. sp. tritici (Pst), is a serious threat to wheat production. When wheat is susceptible to $\underline{P s t}$ infection, the yield loss is about $10-20 \%$, but it can reach $50 \%$ or even result in no harvest in a pandemic year [1]. The most economical, effective and environmental-friendly method is to breed resistant cultivars, but the narrow genetic basis of wheat restricts its genetic improvement [2] Therefore, it is necessary to provide new wheat germplasms with stripe rust resistance to facilitate wheat resistance breeding.

Leymus mollis (Trin.) Pilger $(2 n=4 x=28$, NsNsXmXm), a wild relative of wheat, possesses large and long spike with numerous spikelets and resistance to multiple abiotic and biotic stresses $[3,4]$. Through wild hybridization and cytogenetic manipulation, different wheat- $L$. mollis derivatives were developed as bridge materials for wheat improvement. Among them, octaploid Tritileymus line M842 ( $2 n=8 x=56$, AABBDDNsNs) carrying many beneficial agronomic traits were identified through cytogenetic methods [5]. Yield and resistance-related genes have been transferred into wheat background in the form of partial amphiploidy, addition lines, substitution lines and translocation lines [6-8]. The 
accurate identification and rapid trace of alien chromosomes or translocated fragments directly affect breeding process [9]. Molecular markers are one of the most convenient methods to identify alien chromosomes due to the high efficiency. The existing markers cannot meet the needs of $L$. mollis chromosome detection in the common wheat background. With the development of next generation sequencing technology and bioinformatics tools, SLAF-seq (specific-locus amplified fragment sequencing) technique has been developed as a high-resolution strategy for large scale de novo discovery and genotyping of SNP [10]. It also provides a strategy for developing markers to detect and track alien chromosomes or genes from wheat wild relatives in the wheat background. Based on the SLAF-seq technology, 507 STS markers of Thinoprum ponticum 1Js chromosomes, 89 specific markers of Thinopyrum elongatum 7E chromosomes, two 2St-chromosome-specific markers, and two 3St-chromosome-specific markers were developed respectively [11-13]. Therefore, SLAF-seq is a feasible method to develop sufficient markers for accurate detection of alien chromatin, which could promote the further exploitation of beneficial genes for wheat genetic improvement. To date, no specific SLAF-based markers have been reported in L. mollis.

In the study, a wheat-L. mollis 2Ns (2D) disomic substitution line 17DM48 with a good level of stripe rust resistance and longer spike was identified from the derivatives of wheat and L. mollis. The chromosome numbers of 17DM48 and its chromosomal inherited behavior in meiosis were surveyed by cytogenetic methods. The chromosomal composition was ascertained using FISH, GISH, molecular markers and a single-nucleotide polymorphism (SNP) array. Specific markers were developed using SLAF-seq for tracing chromosome $2 \mathrm{Ns}$ and improving the selection efficiency. Its agronomic traits and stripe rust resistance were evaluated in the field experiment. This line could serve as a bridge material for wheat genetic improvement to increase stripe rust resistance.

\section{Results}

\subsection{Cytological Characterization of $17 D M 48$}

Root tip cells (RTCs) in mitosis metaphase, pollen mother cells (PMCs) in meiosis metaphase I and anaphase I were observed and counted respectively using an Olympus BX-43 microscope. Of 150 RTCs, 143 (95.33\%) cells contained 42 chromosomes, showing that 17DM48 had the chromosome numbers with $2 n=42$ (Figure 1a). A total of 82 PMCs were observed, 78 PMCs had the chromosome configuration of $2 n=21 \mathrm{II}$ (Figure 1b). No trivalents or quadrivalents were observed at metaphase I, and no chromosomes were lagged at anaphase I (Figure 1c). Consequently, line 17DM48 exhibited high cytological stability.

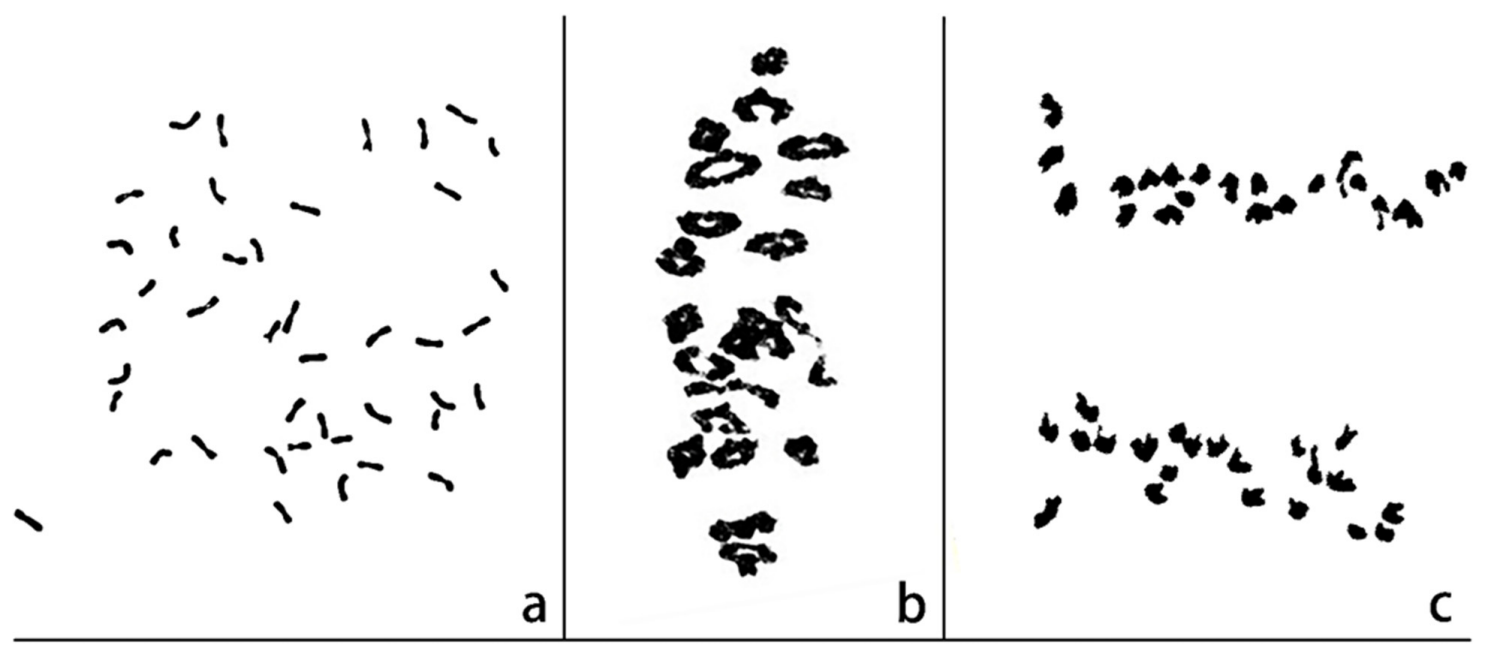

Figure 1. Cytogenetic analysis of 17DM48. (a) root tip cell at mitotic metaphase, $2 n=42$. (b) chromosomal configuration of pollen mother cell at meiotic metaphase, $2 n=21$ II. (c) chromosomal configuration of pollen mother cell at anaphase I, $2 n=21+21$. 


\subsection{GISH and Sequential FISH-GISH Analysis}

Genomic DNA of L. mollis and P. huashanica were used as probe respectively to identify the introduced L. mollis chromosomes in 17DM48. GISH revealed that 17DM48 had two alien chromosomes with green hybridization signals originated from the Ns subgenome of L. mollis (Figure 2a,b).
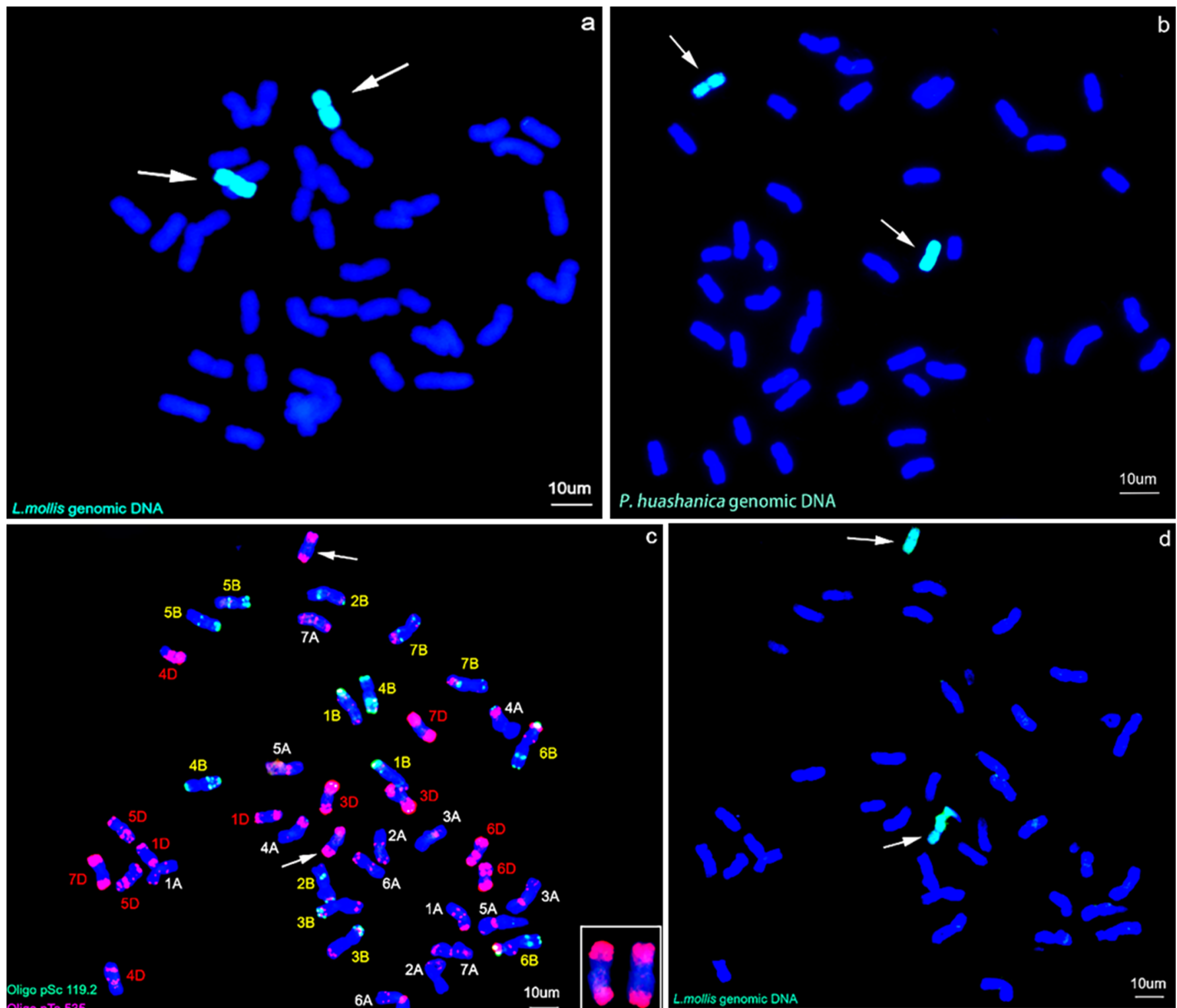

8
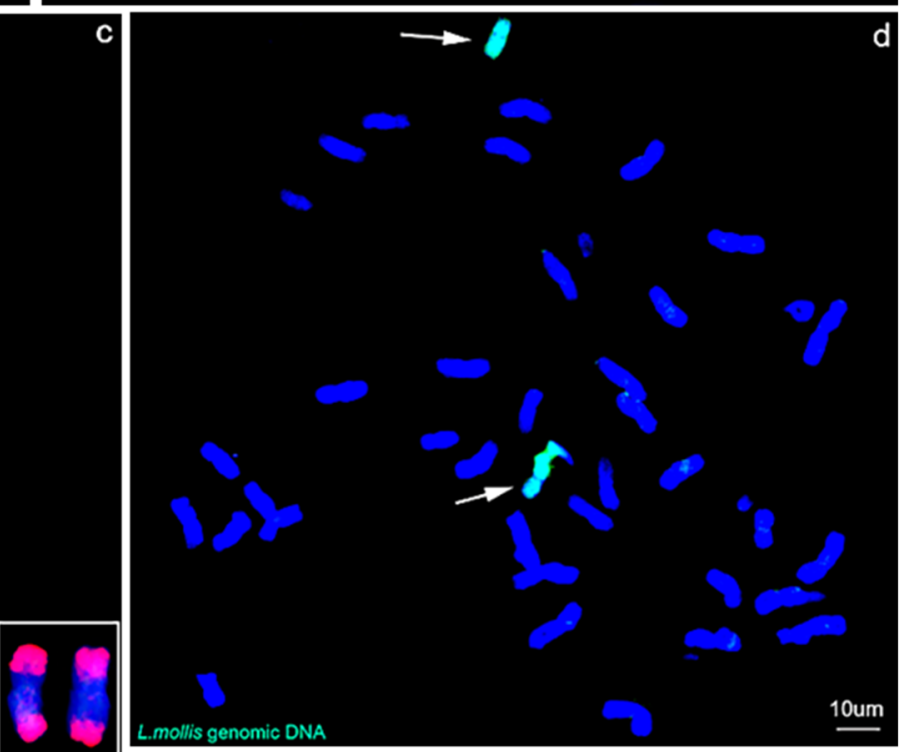

Figure 2. GISH and FISH-GISH analysis on 17DM48. The probes for GISH were L. mollis genomic DNA (green) and P. huashanica genomic DNA (green). (a) GISH detection of 17DM48 using L. mollis genomic DNA as probe (green). (b) GISH detection of 17DM48 using P. huashanica genomic DNA as probe (green). (c) FISH analysis of 17DM48. The probes were Oligo-pSc119.2 (green), and OligopTa535 (red). (d) Sequential FISH-GISH analysis of 17DM48 by the probe of L. mollis genomic DNA. Chromosomes were counterstained using DAPI (blue). The arrows referred to alien chromosomes. Scale bar $=10 \mu \mathrm{m}$.

To determine the chromosome constitution of 17DM48, sequential FISH-GISH analysis was performed. Oligo-pSc 119.2 with green signals and Oligo-pTa535 with red signals, were able to distinguish the 42 wheat chromosomes simultaneously by combining these two oligonucleotide probes. Compared with the standard FISH karyotype of common 
wheat Chinese Spring (CS) [14], it was suggested that 17DM48 lacked a pair of wheat 2D chromosomes and presented two specific ones with the terminal strong binds distributed on both long and short arms by Oligo-pTa535 probe (Figure 2c). Sequential FISH-GISH analysis conducted on the same slide revealed that two extra specific chromosomes had strong signals of L. mollis (Figure 2d), thus corroborating that the lacked 2D chromosomes in 17DM48 were substituted by two Ns chromosomes of L. mollis.

\subsection{Wheat 55K SNP Array Analysis}

A wheat 55k SNP array were employed to further analyze the chromosomal composition of 17DM48. A total of 46,600,48,033, and 28,361 polymorphic SNP loci were identified in 17DM48, 7182, and P. huashanica, respectively (Supplementary Table S1). The maximum, minimum, and mean percentages of SNP genotyping loci shared between 17DM48 and 7182 were $75.87 \%$ (on chromosome 1D), $12.37 \%$ (on 2D), and $53.62 \%$ overall. The maximum, minimum, and mean percentages of SNP genotyping loci shared between 17DM48 and P. huashanica were $29.02 \%$ (on 2D), $4.20 \%$ (on 4D), and $7.04 \%$ overall. Line 17DM48 had the lowest percentage of same SNP loci with its parent line 7182 but shared the highest one with $P$. huashanica. To make a visual comparison, the corresponding positions in chromosome 2D were marked, which had same genotype SNP loci in the same locations in line 17DM48, 7182 , and P. huashanica. It showed that 17DM48 shared more of the same genotype SNP loci in the same locations as P. huashanica rather than line 7182 (Figure 3b). The result indicated that 17DM48 was a wheat-L. mollis 2Ns (2D) disomic substitution line.
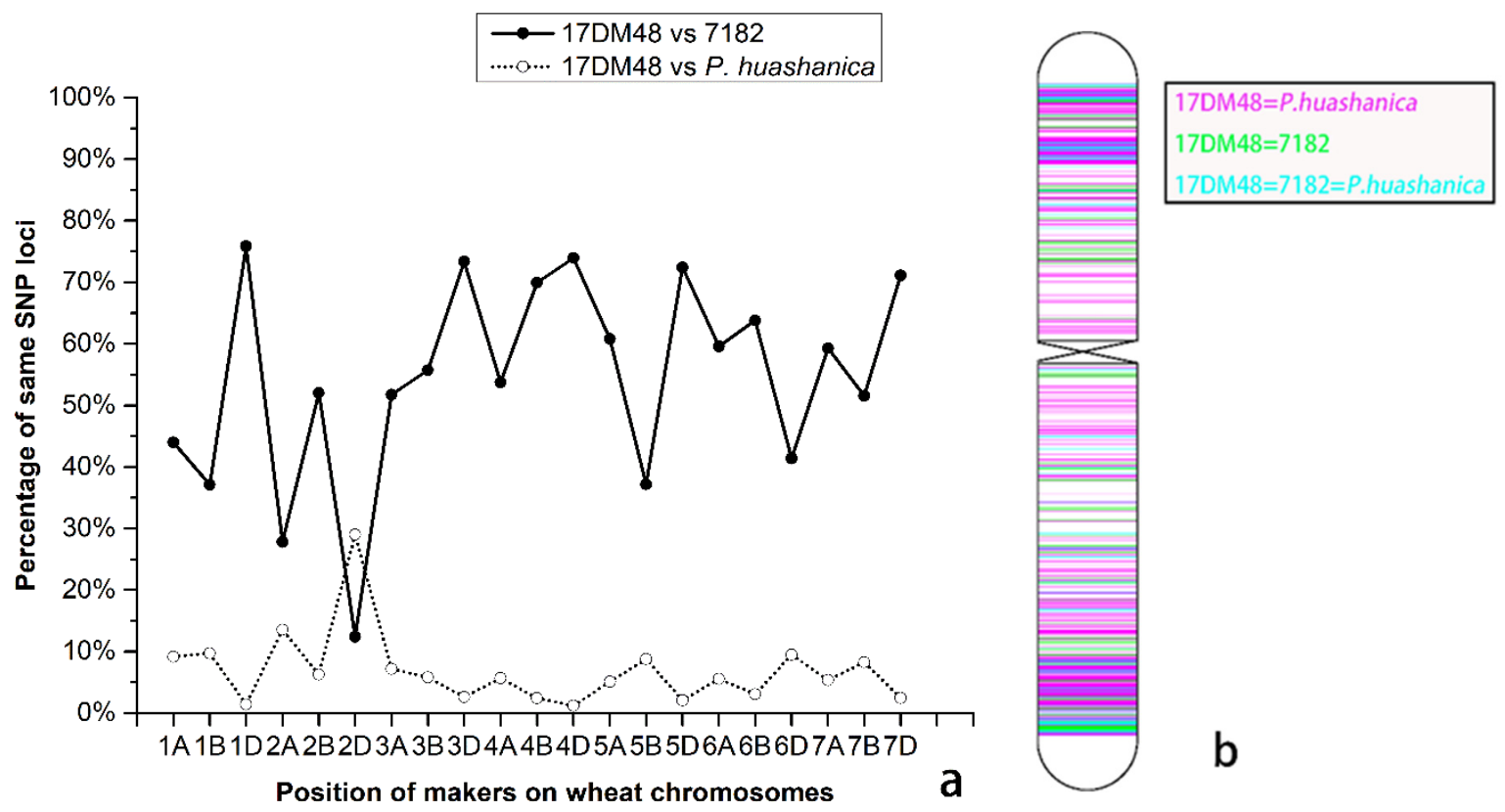

Figure 3. Wheat 55K SNP mapping analysis of 17DM48. (a) Obvious crossing point in terms of the position of the 2D chromosome. (b) Positions of the same SNP loci at the 2D chromosome in the genotype of 17DM48 with P. huashanica and line 7182.

\subsection{Molecular Marker Analysis}

PLUG and EST-STS markers distributed in seven homoeologous groups of wheat were used to verify the homoeologous relationship of alien chromosomes. The results showed that three PLUG markers (TNAC1139-TaqI/HaeIII, TNAC11204-TaqI/HaeIII and TNAC1210-TaqI/HaeIII) and three EST markers (BG607805-2AL/2AS/2BS, BQ1697072AS/2BS/2DS, CD453246-2AS/2BS/2DS) located on the chromosomes of the second homoeologous group amplified expected bands in L. mollis and 17DM48 but not in common wheat line 7182 and the durum wheat line D4286 (Supplementary Table S2, Figure 4). It confirmed that alien chromosomes in 17DM48 belonged to the second homoeologous 
group. The polymorphic markers verified in this study can be used to trace chromosome 2 Ns of L. mollis in wheat background.
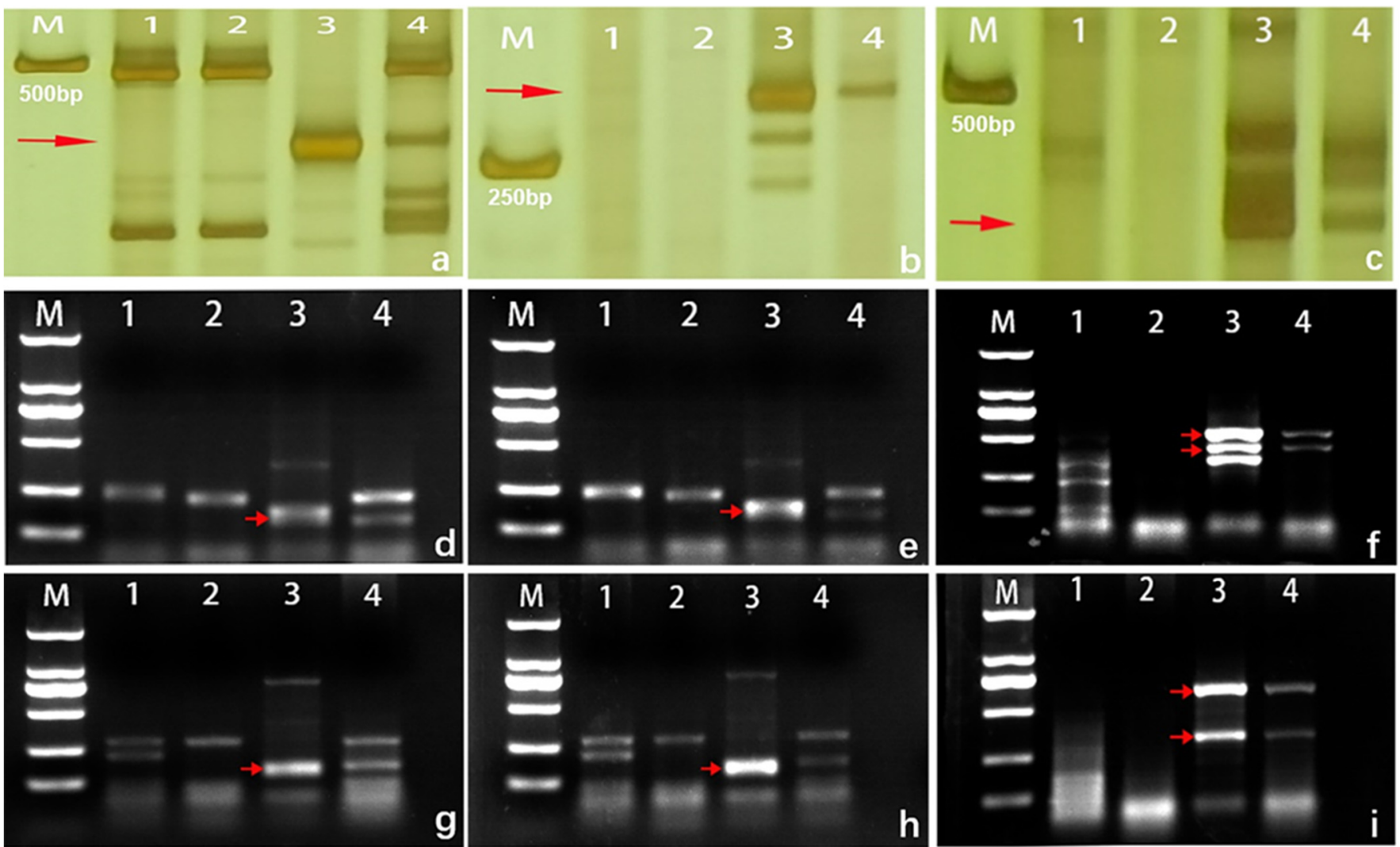

Figure 4. EST-STS and PLUG markers analysis of wheat-Leymus mollis disomic substitution line 17DM48. The red arrows indicate the L. mollis specific band. (M). DNA marker DL2000. (1) 7182. (2) D4286. (3) L. mollis. (4) 17DM48. (a) BG607805. (b) CD453246. (c) BQ169707. (d) TANC1204-TaqI. (e) TANC1210-TaqI. (f) TANC1139-TaqI. (g) TANC1210-HaeIII. (h) TANC1204HaeIII. (i) TANC1139-HaeIII.

\subsection{Evaluation of Agronomic Traits}

The agronomic traits of 17DM48 and its parents were investigated as shown in Table 1. In terms of resistance to stripe rust, line M842 were resistant to stripe rust with infection type 0 , and its derived line 17DM48 displayed a high level of resistance with infection type 1 compared to its parent 7182 and the susceptible control Huixianhong (HXH) (Figure 5). The spike length of 17DM48 was significantly longer than all wheat parents. (Figure 6c). Similarly, the average number of florets and spikelets per spike of 17DM48 was extremely higher than those of its parents (Figure 6d,e).

Table 1. Evaluation of agronomic traits of 17DM48 and its parents.

\begin{tabular}{|c|c|c|c|c|c|c|c|c|c|c|c|}
\hline Material & $\begin{array}{l}\text { Plant } \\
\text { Height } \\
(\mathrm{cm})\end{array}$ & $\begin{array}{c}\text { Tiller } \\
\text { Number }\end{array}$ & $\begin{array}{l}\text { Spike } \\
\text { Length } \\
\text { (cm) }\end{array}$ & $\begin{array}{l}\text { Florets Per } \\
\text { Spike }\end{array}$ & $\begin{array}{l}\text { Spikelets } \\
\text { Per Spike }\end{array}$ & $\begin{array}{l}\text { Kernels } \\
\text { Per Spike }\end{array}$ & $\begin{array}{c}\text { Thousand } \\
\text { Kernel } \\
\text { Weight } \\
\text { (g) }\end{array}$ & $\begin{array}{c}\text { Kernel } \\
\text { Length } \\
(\mathrm{mm})\end{array}$ & $\begin{array}{l}\text { Kernel } \\
\text { Width } \\
(\mathrm{mm})\end{array}$ & $\begin{array}{l}\text { Awn } \\
\text { Type }\end{array}$ & $\begin{array}{c}\text { Stripe } \\
\text { Rust } \\
\text { Reaction } \\
\text { (IT) }\end{array}$ \\
\hline M842 & $\begin{array}{l}86.10 \pm \\
3.32 \mathrm{Aa}\end{array}$ & $9 \pm 5 \mathrm{Bb}$ & $\begin{array}{l}11.75 \pm \\
1.21 \mathrm{Bb}\end{array}$ & $89 \pm 6 \mathrm{BCc}$ & $21 \pm 1 \mathrm{Cc}$ & $\begin{array}{c}43 \pm 17 \\
\mathrm{Bb}\end{array}$ & $\begin{array}{l}34.81 \pm \\
1.27 \mathrm{Cc}\end{array}$ & $\begin{array}{c}8.53 \pm \\
0.08 \mathrm{Aa}\end{array}$ & $\begin{array}{c}3.34 \pm \\
0.03 \mathrm{Dd}\end{array}$ & $\begin{array}{l}\text { short } \\
\text { awn }\end{array}$ & 0 \\
\hline D4286 & $\begin{array}{c}72.88 \pm \\
4.58 \mathrm{Bc}\end{array}$ & $10 \pm 2 \mathrm{Bb}$ & $\begin{array}{l}9.69 \pm \\
0.72 \mathrm{Cc}\end{array}$ & $71 \pm 6 \mathrm{Cd}$ & $24 \pm 1 \mathrm{Bb}$ & $\begin{array}{c}47 \pm 13 \\
\mathrm{Bb}\end{array}$ & $\begin{array}{l}57.01 \pm \\
1.58 \mathrm{Aa}\end{array}$ & $\begin{array}{l}8.08 \pm \\
0.05 \mathrm{Cc}\end{array}$ & $\begin{array}{l}3.56 \pm \\
0.02 \mathrm{Bb}\end{array}$ & $\begin{array}{l}\text { long } \\
\text { awn }\end{array}$ & 1 \\
\hline 7182 & $\begin{array}{c}83.15 \pm \\
5.75 \mathrm{ABab}\end{array}$ & $16 \pm 4 \mathrm{Aa}$ & $\begin{array}{l}11.08 \pm \\
1.04 \mathrm{Bb}\end{array}$ & $109 \pm 7 \mathrm{Bb}$ & $24 \pm 1 \mathrm{Bb}$ & $\begin{array}{c}65 \pm 11 \\
\mathrm{Aa}\end{array}$ & $\begin{array}{l}30.53 \pm \\
1.34 \mathrm{Dd}\end{array}$ & $\begin{array}{c}6.45 \pm \\
0.06 \mathrm{Dd}\end{array}$ & $\begin{array}{l}3.44 \pm \\
0.01 \mathrm{Cc}\end{array}$ & $\begin{array}{l}\text { long } \\
\text { awn }\end{array}$ & 3 \\
\hline 17DM48 & $\begin{array}{l}78.55 \pm \\
7.07 \mathrm{Bb}\end{array}$ & $9 \pm 3 \mathrm{Bb}$ & $\begin{array}{l}19.05 \pm \\
1.34 \mathrm{Aa}\end{array}$ & $\begin{array}{c}203 \pm 34 \\
\mathrm{Aa}\end{array}$ & $28 \pm 2 \mathrm{Aa}$ & $8 \pm 4 \mathrm{Cc}$ & $\begin{array}{l}54.95 \pm \\
1.08 \mathrm{Bb}\end{array}$ & $\begin{array}{l}8.31 \pm \\
0.01 \mathrm{Bb}\end{array}$ & $\begin{array}{c}3.69 \pm \\
0.01 \mathrm{Aa}\end{array}$ & $\begin{array}{l}\text { short } \\
\text { awn }\end{array}$ & 1 \\
\hline Huixianhong & & & & & & & & & & & 4 \\
\hline
\end{tabular}




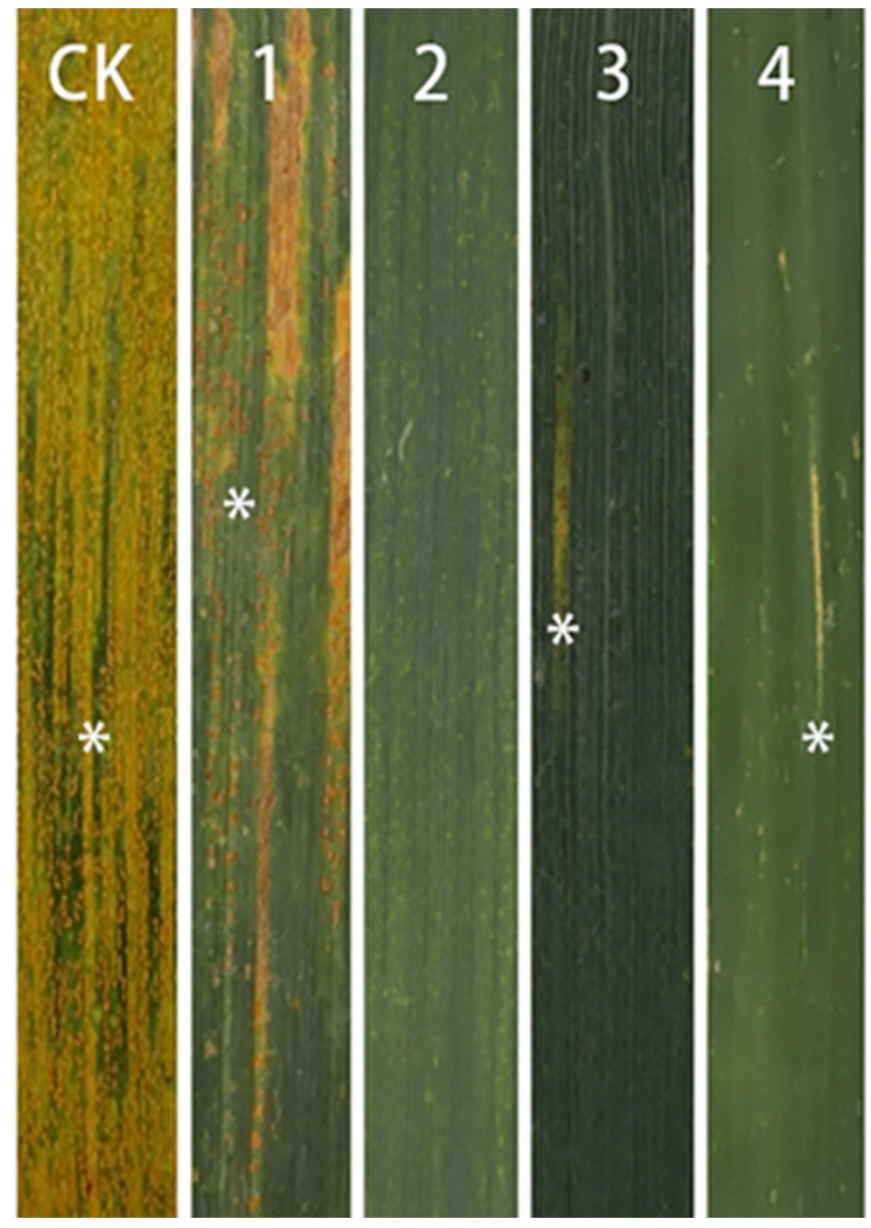

Figure 5. Stripe rust disease reaction of 17DM48 and its parents. (CK) Triticum aestivum Huixianhong. (1) T. aestivum cv. 7182. (2) octoploid Tritileymus M842. (3) T. durum D4286. (4) disomic substitution line 17DM48. Asterisks indicate the symptoms and types of stripe rust reaction.

\subsection{Molecular Marker Development}

A total of 6,643,408 reads were obtained from 17DM48, with the average GC percentage and Q30 percentage of $47.40 \%$ and $94.22 \%$ respectively. 466,330 SLAF numbers were predicted according to the enzyme digestion program. By using BWA and Local BLAST+ tools for analysis, 658 sequences were acquired with $0 \%$ similarity to the reference genome of CS (IWGSC-RefSeqv1.0) and 100\% similarity to the simplified genome of L. mollis (unpublished data), which were considered to be specific sequences of L. mollis.

As expected, 80 primer pairs were designed based on these specific fragments and used for amplifying SLAF sequences from line 7182, D4286, L. mollis and 17DM48. Among them, 13 primers amplified specific bands between L. mollis and 17DM48 with a development success rate up to $16.25 \%$ (Figure 7 , Table 2). These specific markers can be applied to quickly detect the genetic materials carrying $2 \mathrm{Ns}$ chromatin in wheat background, which was the first and successful case in developing efficient markers for detecting alien chromatin in L. mollis. 


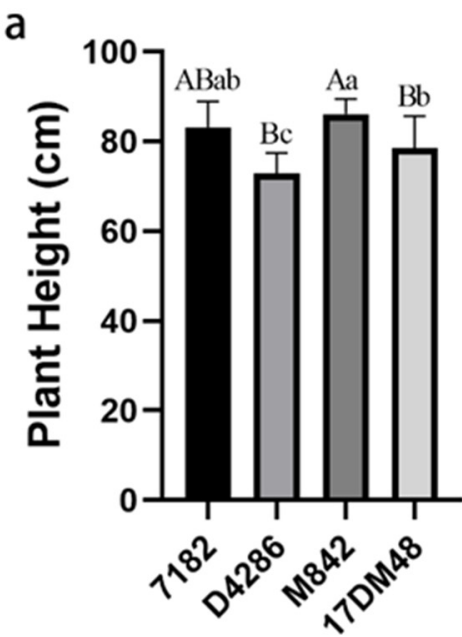

Lines

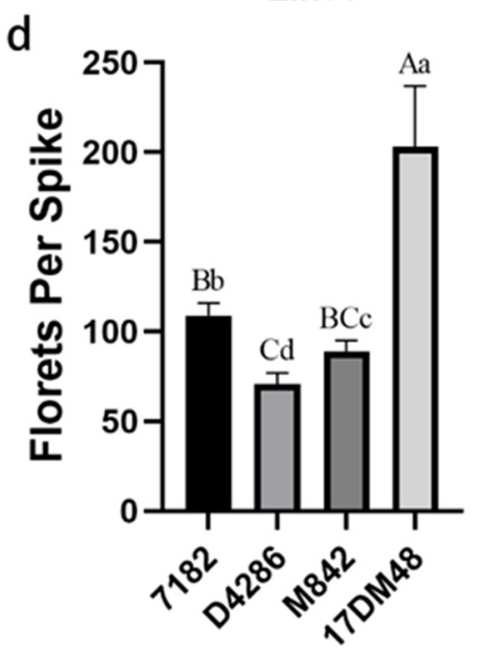

Lines

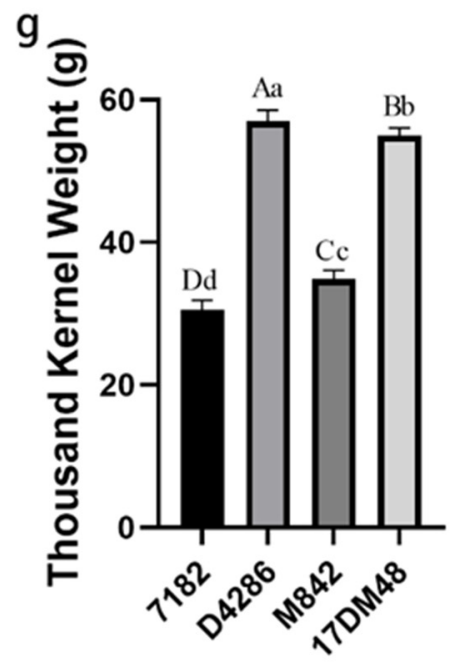

Lines

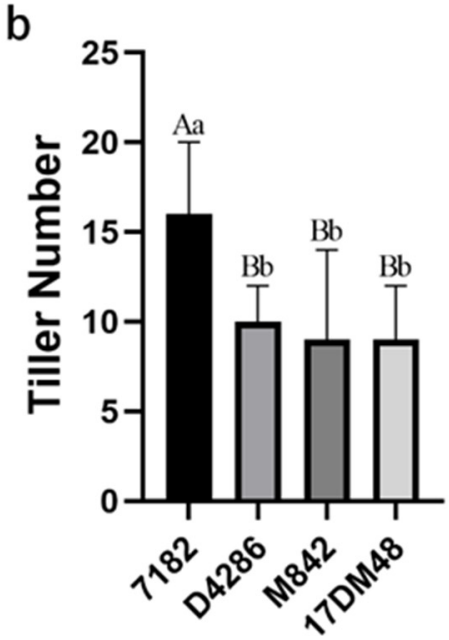

Lines

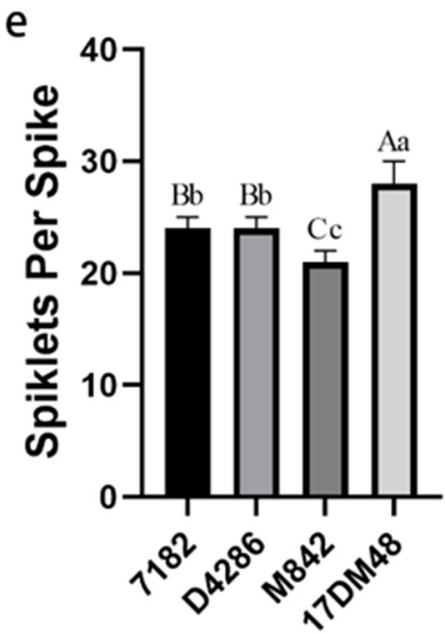

Lines

h

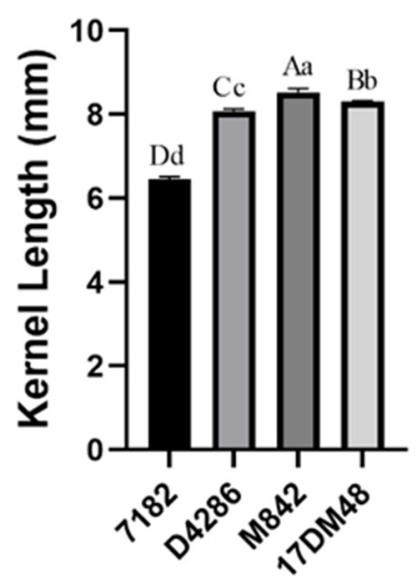

Lines

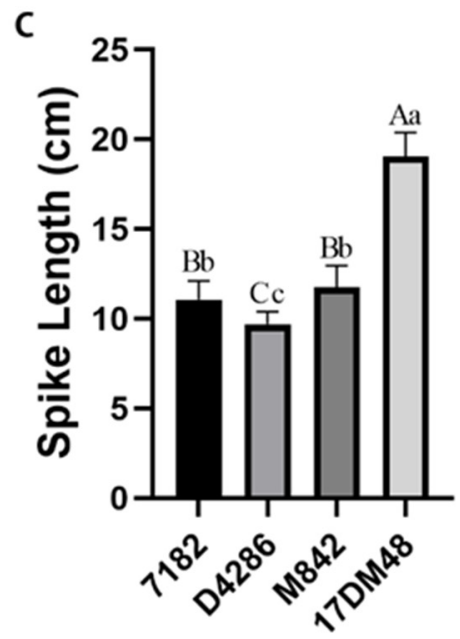

Lines

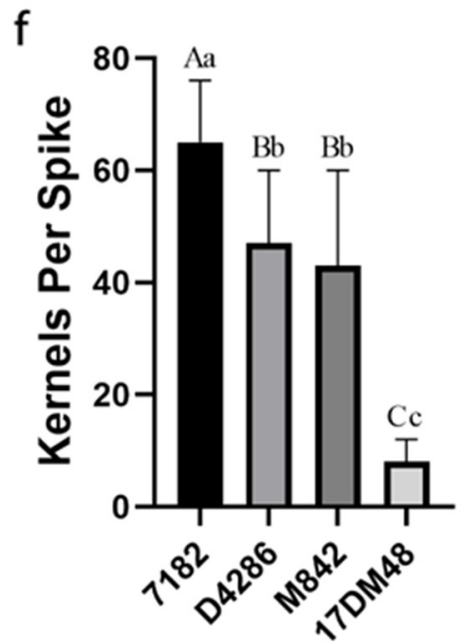

Lines

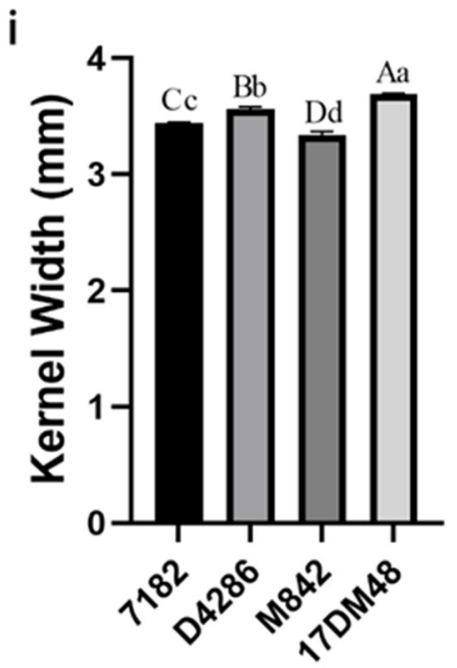

Lines

Figure 6. Analysis of agronomic traits of line 7182 and its parents. (a) plant height. (b) tiller number. (c) spike length. (d) florets per spike. (e) spikelets per spike. (f) kernels per spike. (g) thousand kernel weight. (h) kernel length. (i) kernel width. Capital and small letters indicate significant differences at $p<0.01$ and $p<0.05$, respectively. 

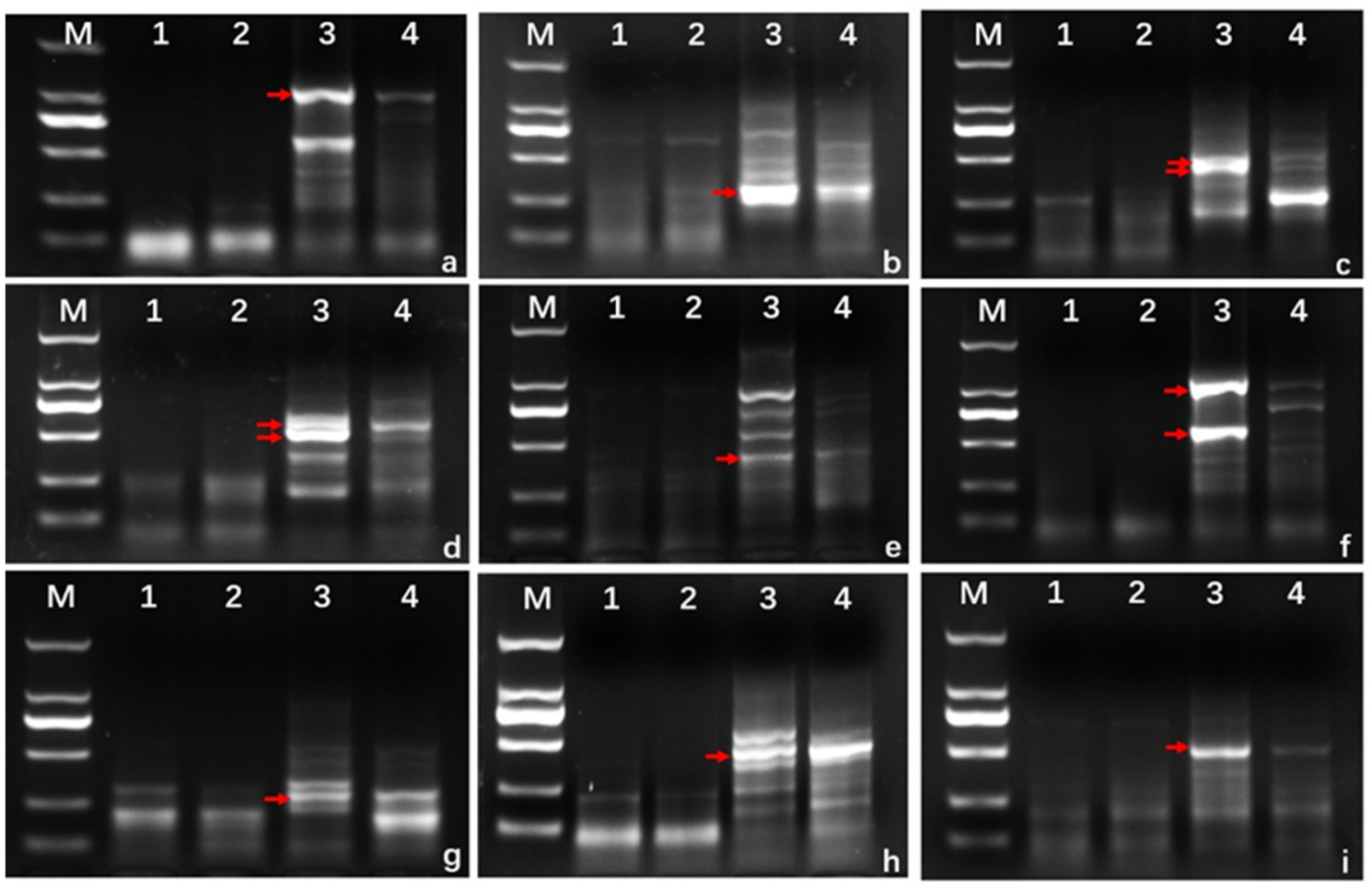

Figure 7. Molecular marker development and PCR amplification of wheat-Leymus mollis disomic substitution line 17DM48. The red arrows indicate the L. mollis specific bands. (M). DNA marker DL2000. (1) 7182. (2) D4286. (3) L. mollis. (4) 17DM48. (a) LM19474. (b) LM19428. (c) LM13006. (d) LM17228. (e) LM25058. (f) LM152390. (g) LM65677. (h) LM224473. (i) LM33865.

Table 2. Specific molecular markers developed for 17DM48 based on SLAF-seq.

\begin{tabular}{|c|c|c|}
\hline Marker & $\operatorname{Tm}\left({ }^{\circ} \mathrm{C}\right)$ & Primer $\left(5^{\prime}-3^{\prime}\right)$ \\
\hline \multirow{2}{*}{ LM19474 } & \multirow{2}{*}{52} & F: TCGTCTGGGTTTGCTTAT \\
\hline & & R: CACCGATTTCCAAGTTTC \\
\hline \multirow{2}{*}{ LM19428 } & \multirow{2}{*}{56} & F: CGTCATCCTCCACCACCT \\
\hline & & R: ACGCAATCTGCTCAACCC \\
\hline \multirow{2}{*}{ LM13006 } & \multirow{2}{*}{56} & F: TGCGGTTGCGTCTATTGG \\
\hline & & R: TGCTGGTGCATCATCATCG \\
\hline \multirow{2}{*}{ LM17228 } & \multirow{2}{*}{56} & F: GCTCCTTTCTCGCTTGCT \\
\hline & & R: TGGACCGCTACGTTTGAC \\
\hline \multirow{2}{*}{ LM25058 } & \multirow{2}{*}{54} & F: AGGAAGGGTCGGAAACTC \\
\hline & & R: AACACCACGGAATGAAGC \\
\hline \multirow{2}{*}{ LM152390 } & \multirow[b]{2}{*}{52} & F: TTTCTAGCCGCTAAAGGT \\
\hline & & R: TTTCCAAGCCTACTCCTG \\
\hline \multirow{2}{*}{ LM65677 } & \multirow{2}{*}{54} & F: CAGAGCATAACCCAGGAG \\
\hline & & R: CCATAGGAACAAGCCAGA \\
\hline \multirow{2}{*}{ LM224473 } & \multirow{2}{*}{54} & F: GGACGGTGAGCAAGAAGG \\
\hline & & R: CGTAATGCCCACGAAACA \\
\hline \multirow{2}{*}{ LM33865 } & \multirow{2}{*}{52} & F: GCTAGTAAATCGGAGGAC \\
\hline & & R: TAGCCATAACACCAATCC \\
\hline \multirow{2}{*}{ LM7529 } & \multirow{2}{*}{52} & F: AGGTTTCCAAATAAGGGAT \\
\hline & & R: CGGACCGTGAATACTCTG \\
\hline \multirow{2}{*}{ LM12508 } & \multirow{2}{*}{54} & F: TCACGGCATACAACAAGG \\
\hline & & R: TATCCACCGACCACTCAA \\
\hline \multirow{2}{*}{ LM23891 } & \multirow[b]{2}{*}{56} & F: TGGGCAACCGATGCTCTA \\
\hline & & R: ACTGGCACGAATCCGTCT \\
\hline \multirow{2}{*}{ LM51499 } & \multirow{2}{*}{56} & F: CAGCAGTGGCTTCTGTTCC \\
\hline & & R: TGTATGTGCGGGAGTGGA \\
\hline
\end{tabular}




\section{Discussion}

Chromosome engineering plays an important role in developing novel germplasm and broadening the genetic base of wheat [15-18]. L. mollis is a beneficial resource for wheat improvement, with resistance genes against multiple fungal diseases and yield improvement potential [19]. The precondition of further utilization of derived lines from chromosome engineering is that alien chromosomes can be stably inherited to the progeny [20]. It is necessary to ensure the chromosome constitution as well as the genetic stability through cytogenetic observation of RTCs and PMCs during mitosis and meiosis, respectively. In this study, a novel wheat-L. mollis 2Ns (2D) substitution line was identified by GISH, FISH, 55K SNP array and molecular marker analysis. The cytology results indicated that 17DM48 had 42 chromosomes, with 21 bivalents in meiosis prophase I and without lagging chromosomes during the chromosome segregation in meiosis anaphase I, and then supported the genetic stability of 17DM48.

Due to the visualized features, GISH and FISH are usually the preferred methods for analyzing germplasm derived from chromosome engineering, and many derived lines, such as addition lines, substitution lines and translocation lines have been successfully identified using these molecular cytogenetic techniques [21-25]. In the study, GISH analysis indicated that a pair of Ns chromosomes from L. mollis were introduced into wheat background (Figure 2a,b). FISH revealed that 17DM48 possessed all chromosomes of common wheat expect two 2D chromosomes. But two chromosomes with unknown karyotype appeared in 17DM48, which were eventually demonstrated to be Ns chromosomes from L. mollis through a sequential FISH-GISH analysis on the same slide. The two alien chromosomes showed large clusters of red fluorescent signals at both ends of the chromosome arms and partially dispersive red signals in the middle (Figure 2c). Above-mentioned karyotype of 2Ns was firstly demonstrated to facilitate the subsequent material identification.

With the development of high-density loci arrays, SNP genotyping has gradually been widely used in gene localization and the determination of alien chromosomes introduced from wheat relatives [26,27]. A wheat-Thinopyrum ponticum 1Js (1D) disomic substitution line, and a wheat-Psathyrostachys huashanica Keng 5Ns (5D) substitution Line were analyzed respectively using wheat SNP arrays [12,28]. In the present study, wheat 55K SNP arrays were employed to determine the chromosome constitution of 17DM48. The results showed that in 17DM48, the same SNPs as its parent 7182 were deleted by $87.63 \%$ on chromosome 2D. On the contrary, compared with P. huashanica, the Ns subgenomic donor of L. mollis, 17DM48 had the highest proportion of the same SNP on chromosome 2D as the second homoeologous group chromosomes of P. huashanica, which indicated that a pair of 2Ns chromosomes originated from L. mollis substituted for wheat 2D chromosomes in 17DM48. Meanwhile, 3 EST-STS markers and 3 PLUG markers distributed in the second homoeologous group of wheat amplified target bands in 17DM48 and L. mollis, while no unique bands appeared in all other parents. These results confirmed that 17DM48 was a wheat-L. mollis 2NS (2D) substitution line, similarly supported by the results of FISH, GISH and SNP arrays.

The SLAF-seq technique, based on next-generation sequencing, has been applied to construct high-density genetic map, develop FISH probes, conduct polymorphism analysis and provide an efficient and convenient method for developing specific PCR-based markers for plants without a reference genome [29]. The increasing SLAF-based markers have been applied in chromosome engineering for rapidly tracing alien fragments. In the study, thirteen specific SLAF markers amplified specific bands in 17DM48 and L. mollis different from those in line 7182 and D4286, which contributes to tracing 2 Ns chromosomes and further mapping of beneficial genes from wheat relatives.

Chromosome rearrangements during evolution widely existed in wheat relatives, including rye, barley, Aegilops, Leymus and other Triticeae species [30-33]. The evolutionary translocations broke down the collinearity between the homoeologous wheat and alien chromosomes, which may lead to the incomplete compensation [34]. In the study, SNP array indicated that chromosome $2 \mathrm{Ns}$ was homoeologous to wheat group 2 and possibly 
showed partial homoeology to three other groups $(1,5,6)$. Previous studies reported that, rye chromosome arms 2RS, 3RL, 4RL, 5RL, 6RS, 6RL, 7RS and 7RL were involved in evolutionary translocations, which paired with wheat chromosomes from a different homoeologous group $[32,35]$. The reciprocal translocation between $4 \mathrm{NsL}$ and $5 \mathrm{NsL}$ had also been proved to occur in Leymus [36]. In this study, through karyotype comparison combined with the results of SNP array, chromosome arm 2NsS was found to show partial homoeology to 6DS, which was possibly caused by the reciprocal translocations between $2 \mathrm{NsS}$ and $6 \mathrm{NsS}$ in the process of evolution. As a likely consequence of the structural differences hence uneven gene dosages and incomplete compensation, it may explain the changes of spike morphology, low seed set and associated changes of kernel size of 17DM48. It was worth mentioning that 17DM48 possessed longer spike than all the parents, with an increased percentage of up to $71.93 \%$ compared to wheat line 7182 . Further mining of corresponding genes contained in 17DM48 would contribute to the genetic improvement of wheat.

Stripe rust is a devastating wheat fungal disease around the world, which causes severe reduction in wheat production in a pandemic year. At present, more than 80 stripe rust resistance genes and related QTLs have been permanently designated in wheat and its relatives [37]. In previous study, several wheat-L. mollis derivatives from different homoeologous groups showed high resistance to stripe rust, involving $5 \mathrm{Ns}$, $6 \mathrm{Ns}$ and 7Ns chromosomes [38,39]. Significantly, in wheat-L.mollis derived lines, both the double monosomic addition line $(2 n=44=42$ T.a + L.m2 + L.m3) [40] and double substitution line $(2 n=42=38$ T.a +2 L.m2 + 2L.m3) [41] were highly resistant to stripe rust, whereas the $3 \mathrm{Ns}(3 \mathrm{D})$ substitution line lacked the stripe rust resistance instead with a leaf rust resistance [42]. It can be inferred that desirable resistant genes against stripe rust probably exist in 2Ns chromosomes of L. mollis. And more research is needed to isolate the potential resistance genes. Breeders prefer translocation lines with smaller alien fragments and less linkage drag, methodology is available to induce chromosome variation [24,43-46]. Finally, it is necessary to develop fine translocation lines involving small L. mollis fragments with desirable agronomic traits for further utilization in wheat improvement programs.

\section{Materials and Methods}

\subsection{Plant Materials}

The plant materials in the present study included bread wheat $7182(2 n=6 x=42$, AABBDD) and Huixianhong (HXH), Leymus mollis $(2 n=4 x=28$, NsNsXmXm), Psathyrostachys huashanica $(2 n=2 x=14$, NsNs), octoploid Tritileymus line M842 $(2 n=8 x=56$, AABBDDNsNs), durum wheat line D4286 $(2 n=4 x=28, \mathrm{AABB})$, and one wheat-L. mollis disomic substitution line 17DM48. The wheat line 7182 was employed as a control in the evaluation of agronomic characters, as well as in molecular marker analysis. The wheat cultivar $\mathrm{HXH}$ was used as a susceptible control in stripe rust evaluation. All the materials mentioned above were deposited in the College of Agronomy, Northwest A\&F University (Yangling, China).

\subsection{Cytological Observation}

The seeds were germinated on moist filter paper in a Petri dish to obtain root tips at a suitable growth period. After nitrous oxide treatment, the root tips were fixed in $90 \%$ acetic acid for $10 \mathrm{~min}$, which subsequently were stored in $70 \%$ ethanol at $-20{ }^{\circ} \mathrm{C}$ for later use. By means of enzymatic hydrolysis with cellulase (R-10, Yakult Japan, Tokyo, Japan) and pectinase (Y-23, Yakult Japan, Tokyo, Japan) at $37{ }^{\circ} \mathrm{C}$ for $1 \mathrm{~h}$, the root tips were made into suspension for sample making, using a production process described by Han et al. [47]. Young panicles at the appropriate stage were sampled, which later were processed with ethanol-chloroform-acetic acid mixture $(6: 3: 1, v / v / v)$ for one week at $25-30{ }^{\circ} \mathrm{C}$. Then, anthers were pinched out and crushed on a slide in $1 \%$ acetocarmine. Root tip chromosome number and pollen mother cells chromosome configuration were 
observed and photographed with an Olympus BX-43 microscope (Olympus Optical Co., Ltd., Tokyo, Japan) equipped with a Photometrics SenSys CCD camera DP80.

\subsection{GISH, FISH and Sequential FISH-GISH}

Before in situ hybridization, chromosomes were fixed for $60 \mathrm{~s}$ at an ultraviolet intensity of $125,000 \mathrm{~mJ} / \mathrm{cm} 2$ by UV irradiation (Spectrolinker ${ }^{\mathrm{TM}}$ XL-1500, Long Island, NY, USA). The total genomic DNA of L. mollis and P. huashanica were used as probe for GISH analysis, which were labeled with Alexa Fluor 488-5-dUTP (Invitrogen, Carlsbad, CA, USA). The CTAB method [48] was performed to acquire highly purified DNA followed by a purification step employing a mixture of 25:24:1 phenol/chloroform/isoamyl alcohol. The GISH hybridization solution consisted of $0.3 \mathrm{~L}$ labelled probe DNA and 8.7 L GISH buffer $(2 \times \mathrm{SSC} / 1 \times \mathrm{TE})$. After the hybridization droplets were added to the slides containing the cell split phase, the chromosomes were denatured along with the probe at $100{ }^{\circ} \mathrm{C}$ for $4 \mathrm{~min}$, and finally renatured at $42^{\circ} \mathrm{C}$ for more than $16 \mathrm{~h}$ [47]. The oligonucleotide probes Oligo-pSc119.2 (green) and Oligo-pTa535 (red) (Shanghai Invitrogen Biotechnology Co. Ltd., Shanghai, China) were used in combination for FISH and latter sequential FISH-GISH analysis [14]. After exposure treatment, GISH analysis was conducted on the same split phase as described earlier. Before microscopy, DAPI was employed to counterstain the chromosomes. Eventually, fluorescent signals were observed and photographed with an Olympus BX-53 microscope equipped with a Photometrics DP80 camera.

\subsection{Wheat SNP Array Analysis}

Genomic DNA of 17DM48 and its parents was hybridized to wheat 55K SNP genotyping arrays, and Illumina Bead Array technology was used for scanning in China Golden Marker Biotechnology Company (Beijing, China). The wheat 55K SNP array contained 49,078 SNPs distributing across 21 pairs of wheat chromosomes. The percentage between two lines containing the same genotype on each chromosome was calculated. Data analysis and graphing were performed to analyze polymorphic markers using Origin V9.1 (OriginLab Corporation, Northampton, MA, USA) and MapChart V2.32 (Wageningen University \& Research, Wageningen, The Netherlands).

\subsection{Molecular Markers Analysis}

Expressed sequence tag-sequence-tagged site (EST-STS) markers (http:/ / wheat.pw. usda.gov/SNP/new / pcr_primers.shtml, accessed on 23 December 2021) and PCR-based Landmark Unique Gene (PLUG) markers [49,50] distributed in homoeologous groups 1 to 7 of wheat chromosomes were synthesized by AuGCT DNA-SYN Biotechnology Co., Ltd. (Beijing, China). To confirm homoeologous group relationships of the introduced alien chromosomes in the wheat-L. mollis disomic substitution line 17DM48, all these molecular markers were employed for polymerase chain reaction (PCR) assays between 7182, D4286, L. mollis and 17DM48. The PCR procedures were carried out as described previously [51]. The PCR products were separated by $8 \%$ non-deformable polyacrylamide gel electrophoresis and visualized after silver staining [52]. The PCR products of PLUG markers were digested with HaeIII $\left(37^{\circ} \mathrm{C}\right)$ for $3 \mathrm{~h}$ or TaqI $\left(65^{\circ} \mathrm{C}\right)$ for $2 \mathrm{~h}$ to increase the polymorphism level. Subsequently, the digested products were separated by $2 \%$ agarose gel electrophoresis. The reagent for the PCR reaction was purchased from Takara Biomedical Technology (Beijing) Co., Ltd. (Beijing, China).

\subsection{Molecular Marker Development}

SLAF-seq of 17DM48 was performed by the Beijing Biomarker Technologies Corporation (Beijing, China). Qualified sample DNA was digested by the restriction enzyme HaeIII. The libraries were sequenced by the Illumina HiSeq platform after passing quality inspection. The data filtering steps are as follows: (1) remove reads with adapter sequences, (2) remove reads with more than $10 \% \mathrm{~N}$ content, (3) remove reads in which more than 
$50 \%$ of the bases had quality scores less than 10 . Sequence quality and data volume were evaluated after filtering sequence readings [53].

Sequences specific to $2 \mathrm{Ns}$ of L. mollis were obtained by Burrows-Wheeler-Alignment V0.1.17 (BWA) [54] and Basic Local Alignment Search Tool V2.10.1 (ftp:/ / ftp.ncbi.nlm.nih. gov/blast/executables/blast+/LATEST/, accessed on 13 August 2021). Sequences with $0 \%$ similarity to CS (IWGSC-RefSeq-v1.0) and 100\% similarity to L. mollis (unpublished data) were selected for molecular markers development. The primers for these sequences were developed using Primer Premier V5.0 (PREMIER Biosoft, Palo Alto, CA, USA). After PCR, specific bands were detected on a $1 \%$ agarose gel.

\subsection{Morphological Traits Evaluation}

All materials were planted in the experimental field of Northwest A\&F University, including 17DM48, parents M842 and D4286, as well as its previous ancestor 7182. At the physiological maturity stage, morphological traits of these lines were evaluated in 2020 and 2021. For each material, ten randomly selected plants were used for the evaluation of agronomic traits, including plant height, tillering, spike length, number of spikelets per spike, number of florets per spikelet, number of kernels per spike, thousand-kernel weight, and awnedness. In addition, each sample is measured for kernel traits through scanning 50 randomly selected kernels. Significant analysis between different materials were conducted using the SPSS Statistics 26 software program (IBM Corp., Armonk, NY, USA). Comparison and graphing of agronomic traits were performed using GraphPad Prism V8.0.1 (GraphPad Software, San Diego, CA, USA).

\subsection{Disease Reaction Evaluation}

7182, D4286, M842, 17DM48, HXH were evaluated for disease reaction to the fungal diseases stripe rust at adult stage. Mixed races of stripe rust fungus (CYR32, CYR33) were used for artificial inoculation. When stripe rust susceptible control variety $\mathrm{HXH}$ was fully infected, the response type was surveyed according to the previous standards [55]. The infection type (IT) standards of wheat stripe rust at adult stage were assessed on a $0-4$ scale as follows: 0 , immune; 0 , nearly immune; 1 , highly resistant; 2 , moderately resistant; 3 and 4 as moderately susceptible and highly susceptible, respectively.

\section{Conclusions}

In this study, a novel wheat-L. mollis $2 \mathrm{Ns}$ (2D) disomic substitution line was identified using cytology methods, DNA markers, SNP array detection, GISH and FISH analysis. The developed line 17DM48 showed a high level of stripe resistance and longer spike. Based on SLAF-seq, thirteen specific markers were developed to identify and trace chromosome $2 \mathrm{Ns}$ of L. mollis in wheat background, thereby further promoting the process of fine mapping of stripe rust resistance genes and molecular marker-assisted breeding. In conclusion, this line has great potential in improving the stripe rust resistance of wheat. It could provide a novel germplasm to transfer stripe rust resistance genes for wheat breeding.

Supplementary Materials: The following supporting information can be found at https:/ /www. mdpi.com/article/10.3390/ijms23052676/s1.

Author Contributions: W.J. and J.Z. conceived and designed the research. X.F. and X.D. performed the research and wrote the article. J.Z. and C.W. contributed to the development of the material. C.C. and L.S. contributed to stripe rust resistance and agronomic trait evaluation. Y.W. and Z.T. collected the data. P.D. and S.W. analyzed the data. All authors have read and agreed to the published version of the manuscript.

Funding: This research was funded by the Shaanxi Research Station of Crop Gene Resources and Germplasm Enhancement Program of China (No. Z100021811).

Institutional Review Board Statement: Not applicable.

Informed Consent Statement: Not applicable. 
Data Availability Statement: All data supporting the findings of this study are available within the paper and within its Supplementary Materials published online. Further information may be obtained from the corresponding author, Wanquan Ji.

Conflicts of Interest: The authors declare no conflict of interest.

\section{References}

1. Wellings, C.R. Global status of stripe rust: A review of historical and current threats. Euphytica 2011, 179, 129-141. [CrossRef]

2. Friebe, B.; Jiang, J.; Raupp, W.J.; McIntosh, R.A.; Gill, B.S. Characterization of wheat-alien translocations conferring resistance to diseases and pests: Current status. Euphytica 1996, 91, 59-87. [CrossRef]

3. Merker, A. The Triticeae in cereal breeding. Hereditas 2008, 116, 277-280. [CrossRef]

4. Fatih, A.M.B. Analysis of the breeding potential of wheat-Agropyron and wheat-Elymus derivatives. Hereditas 2008, 98, 287-295. [CrossRef]

5. Wang, J.; Chen, X.-H.; Du, W.-L.; Zhao, J.-X.; Wu, J.; Cheng, X.-N.; Pang, Y.-H.; Yang, Q.-H.; Liu, S.-H.; Fu, J. Morphological and molecular cytogenetic characterization of partial octoploid Tritileymus. Genet. Resour. Crop Evol. 2013, 60, 1453-1462. [CrossRef]

6. Anamthawat-Jónsson, K. Variable genome composition in Triticum $\times$ Leymus amphiploids. Theor. Appl. Genet. 1999, 99, 1087-1093. [CrossRef]

7. Merker, A.; Lantai, K. Hybrids between wheats and perennial Leymus and Thinopyrum species. Acta Agric. Scand. 1997, 47, 48-51. [CrossRef]

8. Anamthawat-Jónsson, K.; Bodvarsdottir, S.K.; Bragason, B.T.; Gudmundsson, J.; Martin, P.; Koebner, R. Wide hybridization between wheat (Triticum L.) and lymegrass (Leymus Hochst.). Euphytica 1997, 93, 293-300. [CrossRef]

9. Ceoloni, C.; Kuzmanović, L.; Gennaro, A.; Forte, P.; Giorgi, D.; Grossi, M.R.; Bitti, A. Genomes, Chromosomes and Genes of the Wheatgrass Genus Thinopyrum: The Value of their Transfer into Wheat for Gains in Cytogenomic Knowledge and Sustainable Breeding; Springer Science and Business Media LLC: Dordrecht, The Netherlands, 2014; pp. 333-358.

10. Melak, S.; Wang, Q.; Tian, Y.; Wei, W.; Zhang, L.; Elbeltagy, A.; Chen, J. Identification and Validation of Marketing Weight-Related SNP Markers Using SLAF Sequencing in Male Yangzhou Geese. Genes 2021, 12, 1203. [CrossRef]

11. Wang, S.; Wang, C.; Feng, X.; Zhao, J.; Deng, P.; Wang, Y.; Chen, C.; Wang, B.; Ji, W. Molecular Cytogenetics of Chromosome 2St as Well as Chromosome 3St Derived from Thinopyrum Intermedium and Thinopyrum Ponticum; Research Square Platform LLC: Singapore, 2021. [CrossRef]

12. Wang, Y.; Cao, Q.; Zhang, J.; Wang, S.; Chen, C.; Wang, C.; Zhang, H.; Wang, Y.; Ji, W. Cytogenetic Analysis and Molecular Marker Development for a New Wheat-Thinopyrum ponticum 1Js (1D) Disomic Substitution Line with Resistance to Stripe Rust and Powdery Mildew. Front. Plant Sci. 2020, 11, 11. [CrossRef]

13. Chen, S.; Huang, Z.; Dai, Y.; Qin, S.; Gao, Y.; Zhang, L.; Gao, Y.; Chen, J. The Development of 7E Chromosome-Specific Molecular Markers for Thinopyrum elongatum Based on SLAF-seq Technology. PLoS ONE 2013, 8, e65122. [CrossRef]

14. Tang, Z.; Yang, Z.; Fu, S. Oligonucleotides replacing the roles of repetitive sequences pAs1, pSc119.2, pTa-535, pTa71, CCS1, and pAWRC.1 for FISH analysis. J. Appl. Genet. 2014, 55, 313-318. [CrossRef]

15. Nguyen, V.; Fleury, D.; Timmins, A.; Laga, H.; Hayden, M.; Mather, D.; Okada, T. Addition of rye chromosome 4R to wheat increases anther length and pollen grain number. Theor. Appl. Genet. 2015, 128, 953-964. [CrossRef]

16. Silkova, O.G.; Shchapova, A.I.; Shumny̌, V.K. Role of rye chromosome 2R from wheat-rye substitution line 2R(2D) (Triticum aestivum L. cv. Saratovskaya 29-Secale cereale L. cv. Onokhoiskaya) in genetic regulation of meiotic restitution in wheat-rye polyhaploids. Genetika 2007, 43, 971-981. [CrossRef]

17. Silkova, O.G.; Dobrovol'skaia, O.B.; Dubovets, N.I.; Adonina, I.G.; Kravtsova, L.A.; Roder, M.S.; Salina, E.A.; Shchapova, A.I.; Shumnyı̆, V.K. Production of wheat-rye substitution lines and identification of chromosome composition of karyotypes using C-banding, GISH, and SSR markers. Genetika 2006, 42, 793-802. [CrossRef]

18. Lukaszewski, A.J.; Porter, D.R.; Baker, C.A.; Rybka, K.; Lapinski, B. Attempts to Transfer Russian Wheat Aphid resistance from a Rye Chromosomes in Russian Triticales. Crop Sci. 2001, 41, 1743-1749. [CrossRef]

19. Kishii, M.; Wang, R.R.-C.; Tsujimoto, H. Characteristics and behaviour of the chromosomes of Leymus mollis and L. racemosus (Triticeae, Poaceae) during mitosis and meiosis. Chromosom. Res. 2003, 11, 741-748. [CrossRef]

20. Cifuentes, M.; Benavente, E. Wheat-alien metaphase I pairing of individual wheat genomes and D genome chromosomes in interspecific hybrids between Triticum aestivum L. and Aegilops geniculata Roth. Theor. Appl. Genet. 2009, 119, 805-813. [CrossRef]

21. Han, F.; Liu, B.; Fedak, G.; Liu, Z. Genomic constitution and variation in five partial amphiploids of wheat Thinopyrum intermedium as revealed by GISH, multicolor GISH and seed storage protein analysis. Theor. Appl. Genet. 2004, 109, 1070-1076. [CrossRef]

22. Malysheva, L.; Sjakste, T.; Matzk, F.; Röder, M.; Ganal, M. Molecular cytogenetic analysis of wheat-barley hybrids using genomic in situ hybridization and barley microsatellite markers. Genome 2003, 46, 314-322. [CrossRef]

23. Nagy, E.D.; Molnár-Láng, M.; Linc, G.; Láng, L. Identification of wheat-barley translocations by sequential GISH and two-colour FISH in combination with the use of genetically mapped barley SSR markers. Genome 2002, 45, 1238-1247. [CrossRef]

24. Friebe, B.; Kynast, R.G.; Gill, B.S. Gametocidal factor-induced structural rearrangements in rye chromosomes added to common wheat. Chromosom. Res. 2000, 8, 501-511. [CrossRef] 
25. Benavente, E.; Fernández-Calvín, B.; Orellana, J. Relationship between the levels of wheat-rye metaphase I chromosomal pairing and recombination revealed by GISH. Chromosoma 1996, 105, 92-96. [CrossRef]

26. Rasheed, A.; Hao, Y.; Xia, X.; Khan, A.; Xu, Y.; Varshney, R.; He, Z. Crop Breeding Chips and Genotyping Platforms: Progress, Challenges, and Perspectives. Mol. Plant 2017, 10, 1047-1064. [CrossRef]

27. Winfield, M.O.; Allen, A.M.; Burridge, A.; Barker, G.L.A.; Benbow, H.R.; Wilkinson, P.A.; Coghill, J.; Waterfall, C.; Davassi, A.; Scopes, G.; et al. High-density SNP genotyping array for hexaploid wheat and its secondary and tertiary gene pool. Plant Biotechnol. J. 2016, 14, 1195-1206. [CrossRef]

28. Li, J.; Yao, X.; Yang, Z.; Cheng, X.; Yuan, F.; Liu, Y.; Wu, J.; Yang, Q.; Zhao, J.; Chen, X. Molecular cytogenetic characterization of a novel wheat-Psathyrostachys huashanica Keng 5Ns (5D) disomic substitution line with stripe rust resistance. Mol. Breed. 2019, 39, 109. [CrossRef]

29. Sun, X.; Liu, D.; Zhang, X.; Li, W.; Liu, H.; Hong, W.; Jiang, C.; Guan, N.; Ma, C.; Zeng, H.; et al. SLAF-seq: An Efficient Method of Large-Scale De Novo SNP Discovery and Genotyping Using High-Throughput Sequencing. PLoS ONE 2013, 8, e58700. [CrossRef]

30. Naranjo, T. The Effect of Chromosome Structure upon Meiotic Homologous and Homoeologous Recombinations in Triticeae. Agronomy 2019, 9, 552. [CrossRef]

31. Devos, K.M.; Atkinson, M.D.; Chinoy, C.N.; Francis, H.A.; Harcourt, R.L.; Koebner, R.M.D.; Liu, C.J.; Masojć, P.; Xie, D.X.; Gale, M.D. Chromosomal rearrangements in the rye genome relative to that of wheat. Theor. Appl. Genet. 1993, 85, 673-680. [CrossRef]

32. Naranjo, T.; Fernández-Rueda, P. Homoeology of rye chromosome arms to wheat. Theor. Appl. Genet. 1991, 82, 577-586. [CrossRef]

33. Dvorak, J.; Wang, L.; Zhu, T.; Jorgensen, C.M.; Luo, M.-C.; Deal, K.R.; Gu, Y.Q.; Gill, B.S.; Distelfeld, A.; Devos, K.M.; et al. Reassessment of the evolution of wheat chromosomes 4A, 5A, and 7B. Theor. Appl. Genet. 2018, 131, 2451-2462. [CrossRef]

34. Devos, K.M.; Gale, M.D. Extended genetic maps of the homoeologous group 3 chromosomes of wheat, rye and barley. Theor Appl. Genet. 1993, 85, 649-652. [CrossRef]

35. Naranjo, T.; Fernández-Rueda, P. Pairing and recombination between individual chromosomes of wheat and rye in hybrids carrying the ph1b mutation. Theor. Appl. Genet. 1996, 93, 242-248. [CrossRef]

36. Larson, S.R.; Kishii, M.; Tsujimoto, H.; Qi, L.; Chen, P.; Lazo, G.R.; Jensen, K.B.; Wang, R.R.-C. Leymus EST linkage maps identify 4NsL-5NsL reciprocal translocation, wheat-Leymus chromosome introgressions, and functionally important gene loci. Theor. Appl. Genet. 2011, 124, 189-206. [CrossRef]

37. McIntosh, R.; Mu, J.; Han, D.; Kang, Z. Wheat stripe rust resistance gene Yr24/Yr26: A retrospective review. Crop J. 2018, 6, 3-11. [CrossRef]

38. Yang, X.F.; Wang, C.Y.; Chen, C.H.; Tian, Z.R.; Ji, W.Q. Development and characterization of a wheat-Leymus mollis Lm\#7Ns disomic addition line with resistance to stripe rust. Cereal Res. Commun. 2020, 48, 467-476. [CrossRef]

39. Xin, L.I.; Yang, X.; Bing, M.A.; Chen, Z.; Wang, C.; Chen, C.; Tian, Z.; Wanquan, J.I.; Aamp, N.; University, F. Molecular Cytogenetics Identification of a Wheat-Leymus mollis Derivative with Resistance to Stripe Rust. J. Triticeae Crops. 2016, 8, 556-563.

40. Yang, X.; Li, X.; Wang, C.; Chen, C.; Tian, Z.; Ji, W. Isolation and molecular cytogenetic characterization of a wheat-Leymus mollis double monosomic addition line and its progenies with resistance to stripe rust. Genome 2017, 60, 1029-1036. [CrossRef]

41. Zhao, J.; Liu, Y.; Cheng, X.; Pang, Y.; Li, J.; Su, Z.; Wu, J.; Yang, Q.; Bai, G.; Chen, X. Development and identification of a dwarf wheat-Leymus mollis double substitution line with resistance to yellow rust and Fusarium head blight. Crop J. 2019, 7, 516-526. [CrossRef]

42. Pang, Y.; Chen, X.; Zhao, J.; Du, W.; Cheng, X.; Wu, J.; Li, Y.; Wang, L.; Wang, J.; Yang, Q. Molecular Cytogenetic Characterization of a Wheat-Leymus mollis 3D(3Ns) Substitution Line with Resistance to Leaf Rust. J. Genet. Genom. 2014, 41, 205-214. [CrossRef]

43. Falke, K.C.; Sušić, Z.; Wilde, P.; Wortmann, H.; Möhring, J.; Piepho, H.-P.; Geiger, H.H.; Miedaner, T. Testcross performance of rye introgression lines developed by marker-assisted backcrossing using an Iranian accession as donor. Theor. Appl. Genet. 2009, 118, 1225-1238. [CrossRef]

44. Endo, T.R. The gametocidal chromosome as a tool for chromosome manipulation in wheat. Chromosom. Res. 2007, 15, 67-75. [CrossRef]

45. Masoudi-Nejad, A.; Nasuda, S.; McIntosh, R.A.; Endo, T.R. Transfer of rye chromosome segments to wheat by a gametocidal system. Chromosom. Res. 2002, 10, 349-357. [CrossRef]

46. Friebe, B.; Hatchett, J.H.; Gill, B.S.; Mukai, Y.; Sebesta, E.E. Transfer of Hessian fly resistance from rye to wheat via radiationinduced terminal and intercalary chromosomal translocations. Theor. Appl. Genet. 1991, 83, 33-40. [CrossRef]

47. Han, F.; Lamb, J.C.; Birchler, J.A. High frequency of centromere inactivation resulting in stable dicentric chromosomes of maize. Proc. Natl. Acad. Sci. USA 2006, 103, 3238-3243. [CrossRef]

48. Doyle, J. A rapid DNA isolation procedure for small quantities of fresh leaf tissue. Phytochem. Bull. 1987, 19, 11-15.

49. Liu, L.; Luo, Q.; Teng, W.; Li, B.; Li, H.; Li, Y.; Li, Z.; Zheng, Q. Development of Thinopyrum ponticum-specific molecular markers and FISH probes based on SLAF-seq technology. Planta 2018, 247, 1099-1108. [CrossRef]

50. Tiwari, V.K.; Wang, S.; Sehgal, S.; Vrána, J.; Friebe, B.; Kubaláková, M.; Chhuneja, P.; Doležel, J.; Akhunov, E.; Kalia, B.; et al. SNP Discovery for mapping alien introgressions in wheat. BMC Genom. 2014, 15, 273. [CrossRef]

51. Georgieva, M.; Sepsi, A.; Tyankova, N.; Molnár-Láng, M. Molecular cytogenetic characterization of two high protein wheatThinopyrum intermedium partial amphiploids. J. Appl. Genet. 2011, 52, 269-277. [CrossRef]

52. Sanguinetti, C.J.; Dias-Neto, E.; Simpson, A.J. Rapid silver staining and recovery of PCR products separated on polyacrylamide gels. Biotechniques 1994, 17, 914-921. 
53. Bao, Y.; Wang, J.; He, F.; Ma, H.; Wang, H. Molecular cytogenetic identification of a wheat (Triticum aestivum)-American dune grass (Leymus mollis) translocation line resistant to stripe rust. Genet. Mol. Res. 2012, 11, 3198-3206. [CrossRef]

54. Li, H.; Durbin, R. Fast and accurate long-read alignment with Burrows-Wheeler transform. Bioinformatics 2010, $26,589-595$. [CrossRef]

55. Saari, E.E.; Prescott, J.M. A scale for appraising the foliar intensity of wheat disease. Plant Dis. Rep. 1975, 59, 377-380. 